\title{
Airway response to methacholine during exercise induced refractoriness in asthma
}

\author{
HELGO MAGNUSSEN, GABRIELE REUSS, RUDOLF JÖRRES \\ From the Medizinische Universitäts-Poliklinik, Bonn, Federal Republic of Germany
}

ABSTRACT To investigate the mechanisms contributing to refractoriness in exercise induced asthma a methacholine challenge test was performed 30 minutes before and 30 minutes after two exercise tests 45 minutes apart. Exercise was performed by 12 asthmatic patients while they were breathing cold air. There was a smaller airway response to the second exercise test than to the first, though there was wide variation between subjects. The response to the second methacholine challenge was reduced in some patients but showed no significant change overall. Refractoriness to exercise induced asthma positively correlated with a reduced response to methacholine. These data suggest that mediator depletion does not fully explain refractoriness.

Recently Hahn and coworkers showed that refractoriness to exercise induced asthma was not associated with a diminished airway response to histamine. ${ }^{1}$ Since an increase in catecholamine activity with exercise should attenuate the airway response ${ }^{2}$ to both exercise and histamine, these authors favoured mediator depletion as the cause of refractoriness to exercise induced asthma.

Patients with asthma show large variation in their refractoriness in repeated exercise tests. ${ }^{3}$ We therefore carried out a study to determine whether the response to a methacholine challenge performed 30 minutes after two exercise tests 45 minutes apart was related to the degree of refractoriness to exercise induced asthma. Methacholine was chosen because it stimulates airway smooth muscle directly via muscarinic receptors, whereas histamine induced bronchoconstriction is mediated by both direct and indirect pathways. $^{4}$

\section{Methods}

\section{PATIENTS}

We studied 12 patients with bronchial asthma, six men and six women with a mean age of 24 years (range

Address for reprint requests: Professor Dr Helgo Magnussen, Krankenhaus Grosshansdorf, Zentrum für Pneumologie und Thoraxchirurgie, LVA Freie und Hansestadt Hamburg, Wöhrendamm 80, 2070 Grosshansdorf, Federal Republic of Germany.

Accepted 24 March 1986
16-47). All patients had a history of exercise induced asthma. Before entering the study all showed an appreciable decrease in specific airway conductance (sGaw) after an exercise test, and all were hyperreactive to inhaled methacholine. All were nonsmokers and none required regular medication. Sympathomimetic agents were taken occasionally and withheld at least six hours before the study. The patients were instructed about the aim of the study and gave their written consent.

\section{LUNG FUNCTION MEASUREMENT}

Airway resistance (Raw) during quiet breathing and thoracic gas volume at functional residual capacity were determined by a constant volume body plethysmograph (Bodytest, E Jaeger, West Germany). Raw was multiplied by the corresponding thoracic gas volume to give specific airway resistance and converted to specific airway conductance, sGaw. The values were computed on line as the average of four respiratory cycles with a data processor (PDP 11/04).

\section{EXER CISE TEST}

Patients breathed cold air for four minutes while sitting quietly on a bicycle ergometer before exercise, according to the method of Deal et al. ${ }^{5}$ They then exercised for four minutes, after which they continued to breathe cold air through the same mouthpiece for a further four minutes. Lung function was measured before (baseline values) and 3, 10, 15, and 30 minutes after the end of cold air breathing.

Cold air (around $-15^{\circ} \mathrm{C}$ ) was produced by passing dried room air through a heat exchanger. Inspiratory 
and expiratory temperatures were measured by two thermocouples mounted within the two ports of a two way Hans-Rudolf valve. The water content of both inspired and expired air was calculated from standard saturation-temperature curves assuming $100 \%$ humidity. ${ }^{6}$ Expired air was conducted through a heated pneumotachograph (Fleisch No 4) and airflow was electronically integrated to give tidal volume. Respiratory heat exchange was calculated from the equation given by Deal et al. ${ }^{5}$

\section{METHACHOLINE CHALLENGE}

Bronchial challenge with methacholine was carried out according to the guidelines proposed by Chai et al. ${ }^{7}$ A DeVilbiss No 649 nebuliser was triggered by a breath activated solenoid valve that remained open for 0.6 seconds at the beginning of inspiration. The aerosol was generated with pressurised oxygen at $20 \mathrm{lb} / \mathrm{in}^{2}(138 \mathrm{kPa})$. The mean (SD) output of the nebuliser was $0.011(0.002) \mathrm{ml}$ per nebulisation. The diluent (saline) and each concentration of methacholine were administered during five inspiratory breaths from functional residual capacity to total lung capacity at a flow of around $21 \mathrm{~s}^{-1}$.

To standardise the time for performing the challenge six methacholine solutions of doubling concentrations were inhaled. The starting concentration of methacholine was adjusted for each subject on the basis of previous tests to ensure a decrease of sGaw of at least $50 \%$, and ranged from 0.0075 to $0.03 \mathrm{mg} / \mathrm{ml}$.

Lung function was determined before the challenge and three minutes after inhalation of the diluent and methacholine. The provocation dose causing a decrease in sGaw of $50 \%$ ( $\left.\mathrm{PD}_{50} \mathrm{sGaw}\right)$ was obtained from individual dose-response curves in which sGaw was plotted against cumulative breath units (CBU) of methacholine. ${ }^{7}$
EXPERIMENTAL PROTOCOL

All measurements were performed between 1300 and 1700 hours to minimise the influence of circadian rhythm. A methacholine challenge was carried out initially and followed 30 minutes later by an exercise test, which was followed 45 minutes later by a second exercise test at an identical work load. A second methacholine challenge was started 30 minutes after the end of the second exercise test.

\section{DATA ANALYSIS}

The airway response to exercise was expressed as the maximal percentage fall in sGaw from baseline $(\Delta \%$ $s G a w)$. A refractory index (RI) was calculated according to the following equation, where (1) and (2) refer to the first and second exercise test:

$$
\operatorname{RI}(\%)=100 \times \frac{(\Delta \% \text { sGaw }(1)-\Delta \% \text { sGaw }(2))}{\Delta \% \text { sGaw }(1)}
$$

RI $=100 \%$ indicates no airway response to the second exercise test, while RI $=0 \%$ indicates an identical response in the two tests. Geometric mean PD50 sGaw values were calculated; for other measurements arithmetic mean values and standard deviations were used. Non-parametric statistical tests were used to avoid special assumptions on the distribution of data. The four baseline values were compared by Friedman two way analysis of variance ${ }^{8}$ and airway responses, ventilation, and respiratory heat exchange by the Wilcoxon matched pairs signed ranks test. ${ }^{8}$ The relationship between $R I$ and $P_{50}$ sGaw values before and after exercise was analysed with the Spearman rank correlation coefficient. $^{8}$ Statistical significance was assumed when $p<0.05$ for two tailed tests.

Table 1 Baseline specific airway conductance (sGaw), maximum percentage fall in sGaw ( $\Delta \%$ sGaw) after the first (1) and second (2) exercise tests, and refractory index (RI) in 12 asthmatic patients

\begin{tabular}{|c|c|c|c|c|c|}
\hline \multirow{2}{*}{$\begin{array}{l}\text { Patient } \\
\text { No }\end{array}$} & \multicolumn{2}{|c|}{ Baseline sGaw $\left(\mathrm{s}^{-1} \mathrm{cmH}_{2} \mathrm{O}^{-1}\right)$} & \multicolumn{2}{|c|}{$\Delta \%$ sGaw } & \multirow[b]{2}{*}{$R I \%$} \\
\hline & 1 & 2 & $I$ & 2 & \\
\hline $\begin{array}{l}1 \\
2 \\
3 \\
4 \\
5 \\
6 \\
7 \\
8 \\
9 \\
10 \\
11 \\
12 \\
\text { Mean } \\
\text { SD }\end{array}$ & $\begin{array}{l}0.088 \\
0.109 \\
0.078 \\
0.168 \\
0.084 \\
0.077 \\
0.146 \\
0.119 \\
0.057 \\
0.116 \\
0.088 \\
0.076 \\
0.100 \\
0.032\end{array}$ & $\begin{array}{l}0.142 \\
0.110 \\
0.061 \\
0.133 \\
0.081 \\
0.090 \\
0.123 \\
0.124 \\
0.068 \\
0.091 \\
0.100 \\
0.075 \\
0.100 \\
0.027\end{array}$ & $\begin{array}{l}41 \\
63 \\
52 \\
54 \\
66 \\
49 \\
68 \\
53 \\
44 \\
61 \\
74 \\
42 \\
55 \\
11\end{array}$ & $\begin{array}{l}19 \\
46 \\
47 \\
30 \\
44 \\
34 \\
56 \\
61 \\
47 \\
47 \\
70 \\
37 \\
45 \\
14\end{array}$ & $\begin{array}{r}54 \\
27 \\
8 \\
44 \\
34 \\
29 \\
18 \\
-15 \\
-6 \\
23 \\
5 \\
12 \\
19 \\
20\end{array}$ \\
\hline
\end{tabular}


Table 2 Baseline sGaw and $P D_{50}$ sGaw for methacholine challenge before (1) and after (2) the two exercise tests

\begin{tabular}{|c|c|c|c|c|}
\hline \multirow{2}{*}{$\begin{array}{l}\text { Patient } \\
\text { No }\end{array}$} & \multicolumn{2}{|c|}{$\begin{array}{l}\text { Baseline sGaw } \\
\left(s^{-1} \mathrm{~cm} \mathrm{H}_{2} \mathrm{O}^{-1}\right)\end{array}$} & \multicolumn{2}{|c|}{$\begin{array}{l}P D_{50} s G a w \\
(C B U)\end{array}$} \\
\hline & $I$ & 2 & $l$ & 2 \\
\hline 1 & 0.130 & 0.194 & $0 \cdot 19$ & 0.89 \\
\hline 2 & 0.125 & 0.111 & $1 \cdot 58$ & $1 \cdot 70$ \\
\hline 3 & $0 \cdot 119$ & 0.083 & 1.41 & $1 \cdot 50$ \\
\hline 4 & 0.155 & 0.206 & 1.06 & $2 \cdot 11$ \\
\hline 5 & 0.082 & 0.084 & 0.89 & $2 \cdot 81$ \\
\hline 6 & 0.108 & 0.103 & 6.68 & $7 \cdot 29$ \\
\hline 7 & 0.200 & 0.125 & 0.14 & 0.71 \\
\hline 8 & 0.120 & 0.115 & 0.21 & 0.09 \\
\hline 9 & 0.082 & 0.078 & 6.00 & 3.55 \\
\hline 10 & 0.079 & 0.129 & 3.55 & $4 \cdot 22$ \\
\hline 11 & $0 \cdot 141$ & $0 \cdot 129$ & $1 \cdot 50$ & $1 \cdot 25$ \\
\hline 12 & 0.081 & 0.077 & $2 \cdot 51$ & 1.88 \\
\hline Mean & 0.119 & $0 \cdot 119$ & $1 \cdot 17^{*}$ & $1 \cdot 57^{*}$ \\
\hline $\mathrm{SD}$ & 0.036 & 0.042 & $\begin{array}{l}4 \cdot 27 \\
0 \cdot 32\end{array}$ & $\begin{array}{l}4 \cdot 77+1 S D \\
0 \cdot 51-1 S D\end{array}$ \\
\hline
\end{tabular}

${ }^{*}$ Geometric mean with standard deviations.

CBU-cumulative breath units.

\section{Results}

\section{EXER CISE TEST}

Mean baseline values of sGaw did not differ significantly between the first and the second exercise test (table 1). Minute ventilation and respiratory heat exchanged were similar for the two exercise tests, the average values being $37.01 \mathrm{~min}^{-1}$ and $0.981 \mathrm{kcal} / \mathrm{min}$ $(4 \cdot 1 \mathrm{~kJ} / \mathrm{min})$ respectively. The mean (SD) maximal decrease in sGaw was $55 \%(11 \%)$ in the first and $44 \%(14 \%)$ in the second exercise test (table 1$)$, the difference between the two tests being significant ( $p<$ $0.01)$. The mean (SD) refractory index of $19 \%(20 \%)$ was significantly different from zero. The refractory

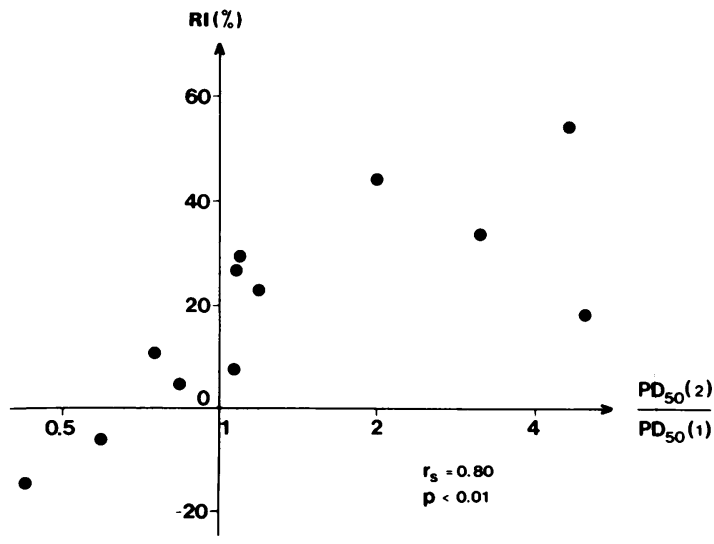

Relationship between refractory index ( RI-see p 668 under "Data analysis") and ratio of $P D_{50}$ values (the provocation doses of methacholine causing a $50 \%$ decrease in sGaw) obtained before (1) and after (2) the dual exercise test. $r_{\mathrm{s}}$-Spearman rank correlation coefficient. index of different subjects covered a wide range, from $54 \%$ to $-15 \%$. The degree of refractoriness did not correlate with the airway response evoked by the first exercise test.

\section{METHACHOLINE CHALLENGE}

The baseline values of $\mathrm{sGaw}$ and $\mathrm{PD}_{50}$ sGaw values did not differ significantly between the two methacholine challenge tests (table 2). There was no significant difference between methacholine and exercise baseline values. The geometric mean $\mathrm{PD}_{50} \mathrm{SGaw}$ values $-1.17 \mathrm{CBU}$ before and 1.57 CBU after the exercise tests (table 2 ) did not differ significantly.

\section{REFRACTORY INDEX AND METHACHOLINE} CHA LLENGE

The refractory index (figure) for the two exercise tests was related to the ratio of methacholine PD $_{50}$ sGaw measured before and after the two exercise tests $\left(r_{s}=0.80\right)(p<0.01)$.

\section{Discussion}

This study is similar to that of Hahn and colleagues ${ }^{1}$ in looking at the relationship between exercise induced refractoriness to asthma and the airway response to an inhaled bronchoconstrictor agent, histamine or methacholine. Hahn et al ${ }^{1}$ found refractoriness to exercise bronchoconstriction but not to histamine bronchoconstriction. In our patients we would draw a similar conclusion if we considered only the mean values. There was a positive correlation, however, between exercise induced refractoriness and a decrease in airway reactivity to methacholine, so that appreciable exercise induced refractoriness was associated with a decreased responsiveness to methacholine. This observation argues against mediator depletion as the sole explanation for the exercise induced refractory period. Our data suggest that in asthmatic subjects showing refractoriness there must be additional mechanisms protecting airway smooth muscle from further stimuli.

There are several possible reasons why these results differ from those of Hahn et al. ${ }^{1}$ Their patients were selected on the basis of similar refractoriness to asthma on repeated exercise tests whereas our subjects covered a wide range of refractoriness - in keeping with asthmatic subjects in general. ${ }^{3}$ Furthermore, Hahn et al induced a greater degree of bronchoconstriction since the $\mathrm{FEV}_{1}$ fell by $43 \%$ in their first exercise study. We obtained a decrease of sGaw of $50 \%$, which would be expected to be associated with a decrease in $\mathrm{FEV}_{1}$ of $16 \%{ }^{8}$ Thus the baseline values for the second histamine challenge were significantly lower than those for the first histamine challenge test in the study of Hahn et al and this may have obscured 
a change in histamine reactivity during the period of exercise induced refractoriness. In addition, the degree of refractoriness may have been overestimated in their study since their patients' $F^{\prime} V_{1}$ had not completely returned to its initial value before the second exercise test. Most of the differences in our results could be explained by these differences in baseline values, which we avoided by our experimental design. This view is supported by a recent survey on exercise induced refractoriness. ${ }^{10}$

Exercise and hyperventilation induced bronchoconstriction differ in many respects, ${ }^{1112}$ though Ben-Dov et al ${ }^{13}$ showed that the degree of refractoriness after exercise and after hyperventilation is similar. In a study of isocapnic hyperventilation in 19 asthmatic patients eight were not refractory to a second challenge. ${ }^{14}$ Significant protection from cholinergic blockade with ipratropium bromide was observed in the patients showing no refractoriness after hyperventilation. The authors suggested that asthmatic subjects with little refractoriness had a vagally mediated airway response to exercise or hyperventilation, while in patients with appreciable refractoriness mediator depletion may play a part. ${ }^{14}$ In these patients other factors, such as the accumulation of catecholamines, may have a role.

\section{References}

1 Hahn AG, Nogrady SG, Tumilty D Mc, Lawrence SR, Morton AR. Histamine reactivity during the refractory period after exercise induced asthma. Thorax 1984;39:919-23.

2 Warren JB, Dalton N, Turner C, Clark TJH. Protective effect of circulating epinephrine within the physiological range on the airway response to inhaled histamine in nonasthmatic subjects. $J$ Allergy Clin Immunol 1984;74:683-6.

3 Schoeffel RE, Anderson SA, Gillam I, Lindsay DA. Multiple exercise and histamine challenge in asthmatic patients. Thorax 1980;35:164-70.

4 Holtzmann MJ, Sheller JR, Dimeo M, Nadel JA, ® Boushey HA. Effect of ganglionic blockade on bron- ڤొ chial reactivity in atopic subjects. Am Rev Respir Dis 1980;122:17-25

5 Deal EC jun, McFadden ER jun, Ingram RH jun, Stra- $\overrightarrow{\vec{\omega}}$ uss RH, Jaeger JJ. Role of respiratory heat exchange in production of exercise-induced asthma. $J$ Appl Physiol 1979;46:467-75.

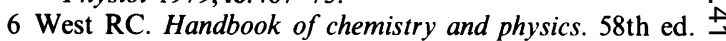
Cleveland, Ohio: CRC Press, 1977.

7 Chai H, Farr RS, Froehlich LA, et al. Standardization of bronchial inhalation challenge procedure. J Allergy Clin Immunol 1975;56:323-7.

8 Magnussen $\mathbf{H}$, Krenko J, Baltzer U, Jörres R. Vergleich spirometrischer und ganzkörperplethysmographischer $\Theta$ Größen bei der Beurteilung der inhalativen Histamin- $\mathbb{D}$ Provokation. Atemw-Lungenkrkh 1985;11:312-4.

9 Siegel S. Nonparametric statistics. New York: McGrawHill Book Company, 1956.

10 Lockhart A, Regnard J, Dessanges JF, Florentin D, Lurie A. Asthme post-exercice et post-hyperventila- $\underset{\infty}{\infty}$ tion. Bull Eur Physiopathol Respir 1985;21:399-409.

11 Bar-Yishay E, Godfrey S. Mechanisms of exerciseinduced asthma. Lung 1984;162:195-204.

12 Magnussen $H$, Scheidt-Mackes M, Kesseler K. Körperliche Belastung und Hyperventilation als auslösende Faktoren der Atemwegsobstruktion beim Asthma bronchiale. Prax Klin Pneumol 1983;37:685-6.

13 Ben-Dov I, Gur I, Bar-Yishay E, Godfrey S. Refractory $\overrightarrow{\overrightarrow{0}}$ period following induced asthma: contributions of exercise and isocapnic hyperventilation. Thorax 1983;38:849-53.

14 Wilson NM, Barnes PJ, Vickers H, Silverman M. Hyperventilation-induced asthma: evidence for two mechanisms. Thorax 1982;37:657-62. 